\title{
Serviço Social em empresas: consultoria e prestação de serviç̧o*
}

\section{Social Work in private companies: consulting and service}

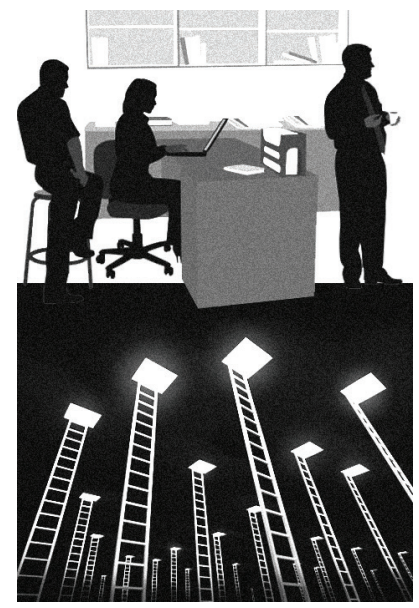

\section{Maria Cristina Giampaoli**}

Resumo: Este artigo apresenta o resultado de pesquisa qualitativa realizada com assistentes sociais, trabalhadores de consultorias empresariais, cujas atividades são terceirizadas para empresas privadas. As consultorias apresentam-se como um possível espaço ocupacional para o profissional, surgido a partir da reestruturação produtiva brasileira. No entanto, na condição de trabalhador terceirizado, ele vivencia o processo de flexibilização e precarização de trabalho.

Palavras-chave: Serviço Social de empresa. Consultoria em Serviço Social. Consultoria. Terceirização.

\begin{abstract}
This article present the result of the qualitative research realized with social workers, business consultants, whose activities are outsourced to private companies. The consultancy firms presents itself as a possible occupational space to the professional, emerged from the brazilian productive restructuring, however, in condition of outsourced worker, the same will experience the process of flexibilization and precariousness of work.
\end{abstract}

Keywords: Social work of company. Consulting in social work. Consulting. Outsourcing.

* Este artigo reproduz parte da dissertação aprovada em maio de 2012, com o título "Contingências no trabalho do assistente em empresas: o caso de consultorias empresariais", no Programa de Estudos Pós-graduados em Serviço Social na Pontifícia Universidade Católica de São Paulo, sob orientação da professora doutora Aldaíza Sposati.

** Assistente social com experiência de 25 anos na atuação profissional em empresas privadas; mestre em Serviço Social pelo Programa de Estudos Pós-graduados em Serviço Social na Pontifícia Universidade Católica de São Paulo _ Brasil.E-mail: cristinaassistentesocial@hotmail.com. 


\section{Introdução}

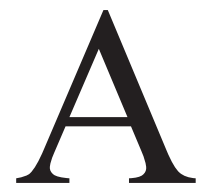

$\mathrm{s}$ análises contidas neste artigo resultam das principais ideias trabalhadas em dissertação de mestrado desta pesquisadora, cujo objetivo foi conhecer o trabalho do assistente social realizado por meio de consultorias, um modo de terceirização da atividade profissional em empresas privadas.

A pesquisa envolveu duas consultorias empresariais, ${ }^{1}$ que, em seu escopo de serviços, terceirizam a atividade de assistentes sociais para empresas. Por meio de entrevistas com dois representantes legais, quatro assistentes sociais e consulta na internet em sites das respectivas consultorias, obteve-se uma visão geral da cultura organizacional, missão, dos objetivos, e, principalmente, da dinâmica do trabalho estabelecida nesse espaço ocupacional, para e pelo assistente social.

Para as reflexões deste artigo, parte-se da realidade social da prática profissional, mediada por questões da reestruturação produtiva do capital, amplamente discutida na literatura do Serviço Social, da qual se destacam os seguintes fatores:

a) o processo de reestruturação produtiva desencadeou mudanças nas operações de diferentes setores da atividade econômica capitalista, alterando estruturas produtivas e, por consequência, o mercado de trabalho;

b) as alterações no mercado de trabalho são evidenciadas a partir de novas formas de contratação, inserção e manutenção do trabalho, além da redução dos postos e consequente desemprego;

c) os efeitos da reestruturação produtiva, conforme Amaral e Cesar (2009), expressam-se pela flexibilização do trabalho e desregulamentação das leis trabalhistas, resultantes de um movimento mais geral da economia mundial que, entre outros efeitos, redirecionaram as estratégias empresariais, de forma a possibilitar uma cultura do trabalho adequada aos requerimentos de produtividade, competitividade e maior lucratividade;

d) nas empresas capitalistas, a partir da necessidade de atender a um mercado globalizado e altamente competitivo, estratégias como privatizações,

1. Em levantamento inicial com profissionais da área de recursos humanos, de 22 empresas, integrantes do Grupo Executivo de Administradores de Benefícios (Geab), foram identificadas cinco consultorias, que prestavam serviços para essas empresas. Priorizaram-se os contatos com quatro consultorias, as sediadas na cidade de São Paulo, mas somente duas aceitaram o convite para participar da pesquisa. 
fusões de empresas, novas formas de produzir mercadorias, marcadas pelas exigências de produtividade, qualidade e rentabilidade, impulsionaram a modernização tecnológica (gerenciais, instrumentais e técnicas), introduziram novas formas de gerenciamento da força de trabalho, novas políticas de administração dos recursos humanos e organização do trabalho, com consequências diretas para o trabalhador.

O assistente social é um profissional assalariado e sua inserção no mercado de trabalho perpassa por condições econômicas e sociais previamente determinadas.

Conforme Raichelis (2011), a reestruturação produtiva do capital atinge o mercado de trabalho do assistente social tanto no setor público quanto no privado. O movimento nas empresas industriais é de mudança e/ou redução de postos de trabalho, enquanto no setor público ocorre a ampliação devido à descentralização dos serviços sociais públicos.

Nas empresas, os postos de trabalho profissional são reduzidos, quer pela não substituição de trabalhadores desligados quer pela absorção das tarefas do profissional por elementos polivalentes, "quanto na transferência das atividades do assistente social para terceiros, na forma de consultoria" (Cesar, 2010, p. 135).

Esses fatores causaram inflexões nas condições de trabalho dos assistentes sociais e, também, reorientaram sua função social, já que novas demandas foram instituídas aos profissionais, incidindo sobre suas competências, atribuições e autonomia. A esse respeito, seguem ainda as seguintes ponderações:

a) Serra (2010), em análise de resultados de sua pesquisa realizada em 1998, com relação ao setor empresarial, pontua que, além da tendência a prevalecer um número reduzido de assistentes sociais por empresa - um e no máximo dois profissionais - , as demandas do Serviço Social sofreram alterações, pois foram centradas não somente na prestação e administração de benefícios, mas também para os programas de formação e qualificação de mão de obra ou de qualidade total, que eram exigências decorrentes da reestruturação produtiva no Brasil, perpassadas por nova racionalidade técnica e ideopolítica;

b) com relação às demandas do profissional, Amaral e Cesar (2009), recorrem a Mota (1985) e descrevem que, nas empresas, o Serviço Social mantém o seu caráter "educativo", voltado para mudanças de hábitos, atitudes e comportamentos do trabalhador, objetivando sua adequação ao 
processo produtivo. O profissional continua sendo requisitado para responder às questões que interferem na produtividade — absenteísmo, insubordinação, acidentes, alcoolismo etc. - ; a intervir sobre os aspectos da vida privada do trabalhador, que afetam seu desempenho - conflitos familiares, dificuldades financeiras, doenças etc. - e a executar serviços sociais asseguradores da força de trabalho.

Esse "pano de fundo" fez-se necessário para fundamentar algumas das implicações que a reestruturação produtiva imprimiu ao mercado trabalho e às condições de trabalho dos assistentes sociais em empresas, com consequências também verificadas no trabalho dos profissionais das consultorias pesquisadas.

Considerando as mudanças ocorridas na forma de inserção desse profissional, por meio das consultorias, apreende-se que, como "atividade-meio" na empresa, o Serviço Social estará (se já não estiver) cada vez mais próximo do processo de terceirização. O desafio que se apresenta ao profissional é o de estabelecer a forma pela qual pretende ingressar nesse espaço, em quais condições, e qual relação social estabelecerá com os demais trabalhadores, a partir dos elementos contidos no seu projeto profissional, na condição de trabalhador também subordinado à exploração pelo capital.

\section{Consultorias empresariais: significados e implicações da função no âmbito da profissão na área do Serviço Social}

O trabalho dos assistentes sociais nas consultorias empresariais passa a integrar o mercado de trabalho profissional a partir de meados dos anos 1990. Contudo, considerando estudos sobre as repercussões da reestruturação produtiva para a profissão, realizados nesse período, por Serra (2010), Mota e Amaral (2010) e Cesar (2010), induz-se que isso se deu sem assegurar as condições e relações de trabalho defendidas pelo Serviço Social brasileiro.

2. As atividades-meio são aquelas consideradas não essenciais à empresa, ou seja, as que têm a finalidade de dar suporte às atividades principais. As atividades-fim são as consideradas principais e estão descritas na cláusula objeto do contrato social das empresas. 
Nas empresas, entre as condições de trabalho estabelecidas no contexto da reestruturação, sobressaem as citadas por Cesar (2010), que dizem respeito à instabilidade e à insegurança sofridas pelos profissionais, devido à redução de postos de trabalho, e responsáveis pelos esquemas de subcontratação por meio da terceirização, ou do estabelecimento de vínculos precários e temporários, que se manifestam também na precarização do trabalho, em termos salariais e de benefícios sociais.

Conforme a autora,

Para os assistentes sociais subcontratados, há uma clara diferenciação: salários mais baixos e [ausência de] benefícios sociais regulados pelo Estado. Para os assistentes sociais efetivos, há uma maior dependência dos benefícios oferecidos [pelas empresas] e os profissionais admitem que tais benefícios acabam prendendo-os à empresa. (Cesar, 2010, p. 136)

Raichelis (2011), em artigo recente a respeito do assunto terceirização, ${ }^{3}$ chama a atenção para a influência nas condições de trabalho do assistente social, nos diferentes espaços institucionais, a partir da dinâmica flexibilização/precarização, que, para além do rebaixamento salarial e perda de benefícios sociais, ocasiona o seguinte:

[...] intensificação do trabalho, aviltamento dos salários, pressão pelo aumento da produtividade e de resultados imediatos, ausência de horizontes profissionais de mais longo prazo, falta de perspectivas de progressão e ascensão na carreira, ausência de políticas de capacitação profissional, entre outros. (p. 422)

Boschetti (2011) também reconhece que os profissionais têm vivenciado, na atualidade, os percalços dos demais trabalhadores, como desemprego, terceirização, informalidade e prestação de serviços sem regulamentação.

Embora não se disponha de dados nacionais sobre as condições de trabalho de assistentes sociais, é óbvio que os efeitos da crise, que impacta de modo destrutivo a vida da classe trabalhadora, atinge igualmente os(as) assistentes sociais. (p. 561)

3. Na bibliografia, exclusiva, do Serviço Social, o assunto terceirização começa a despontar, associado à condição de trabalho do profissional, embora vários autores refiram-se ao processo e às consequências para a classe trabalhadora em geral. 
Assinala que, de maneira geral, o Brasil registrou crescimento no emprego formal, no ano de 2010 , de $6,9 \%$, em relação a 2009 , e, embora represente $50,7 \%$ da população economicamente ativa (PEA) com carteira assinada, a condição de trabalho continua sendo de forte precarização e informalidade, representada por "[...] 49,3\% da PEA sem contrato formal de trabalho e sem acesso aos direitos, como previdência, seguro-desemprego e os demais direitos dependentes do emprego formal" (Boschetti, 2011, p. 561).

$\mathrm{O}$ trabalho do assistente social ${ }^{4}$ enquadra-se, de acordo com a literatura da economia, no setor de serviços. Embora seja um profissional liberal, inserindo-se no conceito de profissões regulamentadas, são trabalhadores, que na grande maioria não dispõem dos meios próprios e instrumentos de trabalho. Podem exercer seu trabalho na qualidade de empregado ou prestador de serviço de forma autônoma.

Na condição de profissional autônomo, sem vínculo trabalhista, o assistente social é obrigado a ter inscrição profissional no Conselho Regional de Serviço Social (Cress). Também necessita inscrever-se e atualizar seus dados no Cadastro de Contribuintes Mobiliários (CCM), na prefeitura do município em que exercerá suas atividades, pois esse tipo de contratação implica o pagamento do Imposto Sobre Serviços de Qualquer Natureza (ISS) ao município. Ainda sobre o assunto, o Cress posiciona-se, para a categoria profissional, como não sendo o órgão competente para ditar exigências de âmbito contratual, e orienta os profissionais a negociarem seus honorários com base na Tabela Referencial de Honorários de Serviço Social (TRHSS).

Quanto à inscrição de pessoa jurídica, visando prestar serviços em assessoria, consultoria, planejamento, capacitação e outros da mesma natureza em Serviço Social, o Conselho Federal de Serviço Social (CFESS) estabelece a obrigatoriedade de registro da pessoa jurídica, assim como o pagamento de anuidade ao Cress.

A Lei n. 8.662, de 7 de junho de 1993, que regulamenta a profissão de assistente social, com relação a assessoria e consultoria, nos artigos $4^{\circ}$ e $5^{\circ}$, refere-se às competências e atribuições do profissional:

4. O Serviço Social é regulamentado como uma profissão liberal, portanto seu exercício profissional necessita de regulação por meio dos conselhos. O Conselho Federal tem a atribuição de regular e fiscalizar o exercício profissional por meio da criação de normas e os conselhos regionais são responsável pela operacionalização da fiscalização em cada região. 
Art. 4 Constituem competências do assistente social:

VIII - prestar assessoria e consultoria a órgãos da administração pública direta e indireta, empresas privadas e outras entidades, com relação às matérias relacionadas no inciso II deste artigo;

IX - prestar assessoria e apoio aos movimentos sociais em matéria relacionada às políticas sociais, no exercício e na defesa dos direitos civis, políticos e sociais da coletividade;

Art. 5ํㅡㄴ Constituem atribuições privativas do assistente social:

III - assessoria e consultoria a órgãos da Administração Pública direta e indireta, empresas privadas e outras entidades, em matéria de Serviço Social. (CFESS, 2011, p. 44-46)

A respeito do tema consultoria, na bibliografia do Serviço Social, além de registrar referência recente, nota-se que mais de um autor conjuga o termo consultoria ao de assessoria. Para Matos (2010), a distinção entre ambos é considerada mínima, por isso ele se refere aos dois processos de forma indistinta. $\mathrm{O}$ autor define assessoria e consultoria como "aquela ação que é desenvolvida por um profissional com conhecimentos na área, que toma a realidade como objeto de estudo e detém uma intenção de alteração da realidade" (p. 31). Portanto, o assessor/consultor deve ser alguém permanentemente atualizado e com capacidades técnica e teórica de apresentar suas proposições.

Para Matos (2009), a assessoria e a consultoria, são atribuições dos assistentes sociais no conjunto das atividades que desenvolvem em seus locais de trabalho, embora seja na universidade que o profissional encontra seu espaço privilegiado.

Lúcia Freire, em artigo que integra o livro organizado por Bravo e Matos (2010), relata a experiência que talvez seja a única na bibliografia do Serviço Social, que se refere à assessoria e consultoria a empresas e aos seus gestores e trabalhadores. Freire (2010), de início, reforça que esse tipo de assessoria e de consultoria é diferente do contratado pelas empresas - consultorias externas - empregadas exclusivamente para profissionais e dirigentes. Baseada nessa relação, a autora questiona, inclusive, por que se assessoram apenas os dominantes (gestores, dirigentes, gerentes) e os pares (profissionais), e não os sujeitos usuários dos programas. A esses, apenas se “"orienta' e 'educa”" (p. 171).

Justifica, ainda, no referido artigo, que tem utilizado a ação de assessorar para todos os sujeitos atendidos pelo Serviço Social, 
Em razão de expressar, de forma mais contundente, a perspectiva democrática de respeito à capacidade desses sujeitos de pensar sobre a sua realidade e elaborar seus planos de ação, nesta perspectiva, o verbo assessorar substitui os verbos assistir, atender, apoiar, encaminhar e a maioria dos compreendidos na ação profissional, na perspectiva de ruptura com o conservadorismo. (In: Freire, 2003, p. 137, nota 1 )

A experiência relatada caracteriza-se como assessoria e consultoria interna, embora esclareça que, na década de 1990, o trabalho não era identificado dessa forma. As demandas de assessoria praticadas e mencionadas pela autora destinaram-se

a gerentes isoladamente, a trabalhadores isoladamente, ou ao conjunto de gerentes ou representantes da empresa e trabalhadores, como na [Comissão Interna de Prevenção de Acidentes] Cipa. Podem ocorrer também demandas temporárias, na introdução de novos projetos e em reestruturações, com grandes pesquisas para obter a adesão de trabalhadores ou um controle diferenciado por eles (muitas vezes, apenas na aparência de que existe um controle social de fato). (Freire, 2010, p. 173)

Freire (2010) destaca que esse espaço na área do trabalho é contraditório, e nele se convive com conflitos de interesses, mas também com consensos. O profissional que coordena o trabalho "em dependência do seu saber teórico-metodológico, de suas habilidades técnico-operacionais e de sua postura ético-político [...]" (p. 173), a partir de sua autonomia (limitada e restrita), poderá utilizá-la no sentido de favorecer mais os trabalhadores ou somente os empresários. Considera que ambos ganham. O empresário e os gestores, por terem os trabalhadores satisfeitos a partir de suas conquistas, produzindo melhor e prestando melhores serviços; e os trabalhadores, pelo mérito no alcance das suas conquistas e, principalmente, pela prática do exercício político.

No entanto, concorda-se com a autora, ao referir que somente os assistentes sociais com perfil qualificado, capacitado e atualizado apresentarão a vantagem de apreender a realidade, no seu cotidiano de trabalho, sem descartar os limites institucionais, e muitas vezes os limites históricos, e contribuirão para constituir novos sujeitos políticos diante da classe trabalhadora.

Na bibliografia da área de administração, que concentra a maioria dos estudos a respeito de consultorias empresariais, constata-se que essa modalidade representa 
o resultado da busca de novas estratégias de gestão, impulsionadas pelas mudanças constantes decorrentes da globalização, pelo avanço tecnológico, pelos novos modelos de competitividade, pela velocidade do processo de especialização, pelas exigências do consumidor, e maximização da qualidade e do lucro, e adentram cada vez mais nas empresas privadas.

Conforme Djalma Oliveira (2004), a consultoria empresarial é um dos segmentos de prestação de serviços que mais tem crescido no mundo, representando um dos campos de trabalho mais procurados por jovens graduados em universidades europeias e americanas. Conforme pesquisa a respeito, a justificativa dada pelos jovens é que esse segmento representa

a possibilidade de maior rapidez na evolução de conhecimentos adquiridos e a percepção de um crescimento do negócio consultoria em relação a outros negócios, principalmente quando comparados aos segmentos da indústria e do comércio. (Oliveira, 2004, p. 24)

Elizenda Orlickas (2001) descreve consultoria como sendo "o fornecimento de determinada prestação de serviço, em geral, por um profissional muito qualificado e conhecedor do tema, provido de remuneração por hora ou projeto, para um determinado cliente" (p. 39).

Conforme a autora, a finalidade do trabalho de consultoria visa a mudança de uma realidade, demonstrando, desta forma, também a necessidade de o consultor estar qualificado por instrução superior e experiência específica. Conforme consta,

Os trabalhos desenvolvidos pelo consultor de organização devem ser realizados visando à introdução de inovações que objetivem auferir um melhor desempenho do cliente, transferindo-lhes todos os conhecimentos necessários à perfeita continuidade do funcionamento dos serviços implantados, jamais retendo elementos ou mantendo reserva sobre conhecimentos que seriam importantes para que o cliente se torne independente em relação ao consultor. (Orlickas, 2001, p. 46)

Oliveira (2004) relaciona o aumento do número de empresas de consultorias a algumas tendências, entre as quais se destaca o objetivo deste artigo, qual seja, o aumento da demanda de consultoria "como consequência dos processos de terceirização" (p. 26). O autor acrescenta que as empresas estão direcionando todos os 
esforços para o núcleo de seu negócio, e, nesse contexto, utilizam a terceirização como estratégia para facilitar o processo. Descreve a terceirização como

processo administrado de transferência, para terceiros, de atividades que não constituem a essência tecnológica dos produtos e serviços da empresa, pois envolvem tecnologias de pleno domínio do mercado e, por conseguinte não consolidam quaisquer vantagens competitivas, quer sejam tecnológicas ou comerciais, além de contribuírem para o aumento dos custos fixos da empresa. (Oliveira, 2004, p. 25-26)

Cita ainda, como exemplos da elevada terceirização, os serviços de recursos humanos e de informática, os quais são transferidos para as consultorias, por representarem melhor qualidade e custos menores. E que, embora os serviços terceirizados, em sua maioria, não sejam considerados como de consultoria empresarial, existem algumas exceções em fase de crescimento, como é o caso da transferência para terceiros (consultores e empresas de consultoria), de algumas atividades que agreguem valor ao produto e serviço oferecidos pela empresa-cliente. A empresa pode decidir "eliminar alguma atividade ou realizar esta situação de maneira indireta, por meio da terceirização" (Oliveira, 2004, p. 82).

As consultorias empresariais envolvidas neste estudo configuram, de maneira geral, a descrição acima feita pelo autor, na medida em que prestam parecer sobre assunto de sua especialidade às empresas contratantes e terceirizam a atividade dos assistentes sociais.

\section{Algumas notas sobre a terceirização: flexibilização e precarização}

Graça Druck e Tânia Franco (2008), a respeito da terceirização, referem-se a Carelli (2003), que conceitua a palavra como uma criação brasileira, revelando o real conteúdo da prática, qual seja, o "repasse ou a transferência de uma atividade a um 'terceiro' ou um 'outro', que deveria se responsabilizar pela relação empregatícia e, portanto, pelos encargos e direitos trabalhistas. Essa transferência é realizada por um "primeiro"” (p. 84). Como não se aborda quem seria o "segundo", as autoras concluem que o termo indica posição periférica, e nos mais diversos setores em que a terceirização se realiza, aponta para uma desqualificação, em geral para uma condição mais baixa, precária, menos central e de subordinação aos "primeiros". 
Conforme relatório técnico elaborado pelo Departamento Intersindical de Estatísticas e Estudos Socioeconômicos (Dieese), ${ }^{5}$ o que se terceiriza é a atividade, e não a empresa ou o trabalhador. "A empresa terceira contrata o trabalhador, que não é terceirizado, mas faz parte do processo de terceirização" (p. 6).

Para Denise Motta Dau (2009), os principais objetivos das empresas, com o processo de terceirização, são custos reduzidos e maior flexibilidade da gestão da força de trabalho em termos de contratação e demissão, "o que para a classe trabalhadora tem significado redução de direitos, maior instabilidade e condições de trabalho, de modo geral, adversas" (p. 169).

É importante destacar que, na visão da autora, as empresas terceirizam tudo o que é possível, caminho apontado pelos empresários como para a modernidade, quando, na realidade, a terceirização no Brasil apresenta pouca relação de modernidade, quando comparada ao modelo japonês, ${ }^{6}$ já que não promove relação de parceria, de especialização, de aperfeiçoamento da qualidade, que orientaram a reorganização da produção e do trabalho no Japão. A prática econômica e a gerencial, nas empresas e organizações em geral, combinadas com o ideário neoliberal, elege a terceirização como prática estratégica para reduzir custos em todos os setores produtivos. A "modernidade" "tem sido mera retórica para legitimar um novo padrão de produção que tem como núcleo a flexibilização e a precarização do trabalho" (Dau, 2009, p. 170).

$\mathrm{Na}$ visão de empresários e consultores, a terceirização gera empregos e contribui para aumentar a especialização e a qualidade dos serviços. Na visão dos sindicalistas, é destruidora de empregos e de direitos, pois, quando uma empresa terceiriza atividades e serviços, o faz para empresas cujo acordo coletivo (quando existente) é negociado em condições inferiores à da grande empresa, além do que a renda, os benefícios e as condições de trabalho apresentam-se superiores ao das pequenas empresas (Dau, 2009).

Graça Druck (1999), com base em informações do Dieese (1994), aborda a terceirização a partir de dois padrões: reestruturante e predatório. No primeiro, a

5. Consulta ao texto: O processo de terceirização e seus efeitos sobre os trabalhadores no Brasil. Disponível em: $<$ htpp://www.mte.gov.br/observatorio/prod03_2007.pdf $>$. Acesso em: 10 dez. 2011.

6. A autora destaca como pontos comuns entre a realidade japonesa e a brasileira, resguardadas as devidas proporções, associados ao novo padrão de produção, a exigência de um novo trabalhador, "polivalente, intercambiável, descartável a qualquer tempo (daí a defesa de contratos flexíveis e a desvinculação de organizações sindicais fortes)" (Dau, 2009, p. 170). 
finalidade é a redução de custos, a partir de determinantes tecnológicos e organizacionais, já que a focalização possibilita ganhos de produtividade e eficiência, ao mesmo tempo que, ante a instabilidade do mercado, permite transferir os riscos para terceiros. Esse padrão estaria relacionado com a qualidade e a produtividade e inserido, portanto, no novo paradigma tecnológico. O segundo padrão é reconhecido, pela autora, como o predominante no Brasil, e definido da seguinte forma:

[...] caracteriza-se pela redução de custos através da exploração de relações precárias de trabalho. Essa terceirização recorre a todas as principais formas de trabalho precário: a) subcontratação de mão de obra; b) contrato temporário; c) contratação de mão de obra por empreiteiras; d) trabalho a domicílio; e) trabalho por tempo parcial; f) trabalho sem registro em carteira. O que se observa, portanto, é uma flexibilização dos direitos trabalhistas, um mecanismo de tentar neutralizar a regulação estatal e a regulação sindical (p. 135-36; grifos nossos)

É certo que um dos processos para entender o que envolve a terceirização seja a "contratação, visto que é evidente o arbitramento na flexibilização dos contratos com terceiros. "A terceirização é uma das principais formas ou dimensões da flexibilização do trabalho, pois ela consegue reunir e sintetizar o grau de liberdade que o capital dispõe para gerir, e, desta forma, dominar a força de trabalho" (Druck e Franco, 2008, p. 84).

Quanto à legislação regulamentadora da terceirização, a polêmica e o debate são intensos e representam, para a classe trabalhadora, um dos maiores problemas, pela inexistência de legislação específica sobre a modalidade no Brasil. ${ }^{7}$

Graça Druck (2009) reporta-se à precarização do trabalho no Brasil como uma característica oriunda do trabalho escravo, e que perdurou até o trabalho assalariado, e do grau de informalidade do trabalho nas regiões de fraco desempenho industrial, como é o caso do Norte e Nordeste. Reconhece também que, em variados momentos históricos, houve conquistas dos trabalhadores, nas formas de proteção social e trabalhistas, identificando, em 1944, a edição da Consolidação das Leis do Trabalho (CLT), o avanço da industrialização e o crescimento da classe operária brasileira.

7. Atualmente, cabe ao direito civil regular o contrato estabelecido entre a empresa contratante e a prestadora de serviço, e ao direito do trabalho regular a relação contratual entre esta última e o trabalhador por ela contratado. 
Assegura, no entanto, que há uma nova precarização social do trabalho, ${ }^{8}$ que atinge tanto as regiões mais desenvolvidas do país quanto as mais tradicionalmente marcadas pela precariedade, e registrada nos setores mais dinâmicos e modernos, nas indústrias de ponta e também nas formas mais tradicionais do trabalho informal, por conta própria, autônomo etc., que atinge tanto os trabalhadores qualificados como os menos habilitados. Por fim, a autora destaca que essa precarização se estabelece e se institucionaliza fragilizando os vínculos e impondo perda "dos mais variados tipos (de direitos, do emprego, da saúde e da vida) para todos os que vivem-do-trabalho" (Druck, 2009, p. 10).

\section{0 caso de consultorias empresariais e os profissionais do Serviço Social}

Identifica-se que as consultorias (A e B) participantes da pesquisa qualitativa têm o perfil de consultoria empresarial, uma vez que fornecem determinada prestação de serviço, a especialização de seus consultores, para as empresas clientes. Os assistentes sociais que prestam serviços por meio das consultorias participantes são denominados de consultores em Serviço Social e consultores de atendimento. Para as empresas clientes, são considerados consultores externos, uma vez que não as integram legal e administrativamente.

Confirma-se a tendência apontada no estudo nacional, realizado pelo CFESS (2005), a respeito das mudanças na nomenclatura dos cargos e funções exercidos pelos profissionais, que tendem a refletir mais as funções e competências do que a formação profissional original.

As consultorias têm características distintas, considerando-se a forma e prestação dos principais serviços, desenvolvidos pelos assistentes sociais, e, por consequência, alteram-se as relações sociais estabelecidas com os empregados das empresas clientes.

A Consultoria A foi constituída em 1998 e tem como característica principal a prestação de serviço especializado em Serviço Social, e, conforme a representante legal, os programas mais contratados pelas empresas são aqueles que envolvem

8. Conforme a autora, é "uma nova precarização" porque foi reconfigurada, ampliada e expressa uma regressão social em todos os seus tipos, e seu caráter atualmente é abrangente, generalizado e central (Druck, 2009). 
o atendimento social e emergencial, bem como o destinado ao acompanhamento de empregados em afastamentos previdenciários. Conforme site da consultoria, por meio desses programas, oferecem atendimento 24 horas para situações de emergência; entrevista social; visitas domiciliar e hospitalar; captação de recursos públicos; suporte social aos gestores, funcionários e familiares; orientação em casos de falecimento, nos âmbitos nacional e internacional; apoio a incidente crítico (violência urbana, acidente de trabalho, entre outros); orientação e acompanhamento decorrentes de desequilíbrio orçamentário; e dependência química.

Para disponibilizar os serviços às empresas clientes, possui 25 profissionais, dos quais dezenove são formados em Serviço Social, ocupando, em novembro de 2011, os seguintes cargos: um diretor, um gerente, dois supervisores e quinze assistentes sociais. Desses, dez são autônomos, e revezam-se na central de atendimento e também de forma presencial nas empresas clientes para a prestação de serviços, e cinco são contratados via CLT, para trabalhar em uma empresa que assim exigiu. Além desses profissionais, a consultoria tem uma rede credenciada composta por 3.500 assistentes sociais, 2 mil psicólogos e alguns advogados, todos autônomos, distribuídos em várias localidades no Brasil. ${ }^{9}$

A Consultoria B foi constituída como empresa limitada, no ano de 2000, e trouxe para o Brasil o conceito de Employee Assistance Programs (EAP) ou, como também é conhecido, Programa de Assistência ao Empregado (PAE). De origem americana, surgido em 1940, inicialmente voltava-se para programas ocupacionais de prevenção e tratamento do alcoolismo. Atualmente, abrange ampla variedade de problemas e consta em $90 \%$ das maiores empresas americanas.

É uma empresa pioneira no Brasil no conceito EAP, considerado um programa que complementa o plano de benefícios sociais oferecidos pelas empresas de grande porte. Para o atendimento, a consultoria tem uma rede credenciada de profissionais especialistas em dependência química, psicologia, psiquiatria, serviço social e direito. Para as questões do Serviço Social atualmente a rede é composta por duzentos assistentes sociais distribuídos no território latino-americano, acionados nas demandas. Todos esses profissionais prestam serviço para a consultoria de forma autônoma.

9. A rede credenciada é composta por profissionais que não atuam internamente na consultoria. Conforme consta no site da empresa, estão localizados nas seguintes cidades: Aracajú, Belém, Belo Horizonte, Brasília, Curitiba, Fortaleza, Goiás, Londrina, Piauí, Porto Alegre, São José, São Luís, São Paulo, Rio de Janeiro, Tocantins, Vitória. A representante da Consultoria A informa que mantém cadastro com três ou quatro profissionais em cada localidade. 
Como descrito no site da consultoria, o programa atende às seguintes demandas: ansiedade, angústia, depressão, pânico e outros problemas emocionais; dificuldades de relacionamento pessoal e profissional; problemas no trabalho; situações de luto ou perda; estresse diário, situações críticas e emergências, como assaltos, sequestros, acidentes e desastres; envolvimento com álcool e drogas; convívio com idosos; crianças com problemas de aprendizagem ou necessidades especiais; dificuldades financeiras ou planejamento financeiro familiar; e orientações sobre questões legais.

A Consultoria B tem, ao todo, 65 profissionais, divididos entre os escritórios de São Paulo e do Rio de Janeiro. Em São Paulo, a equipe da Consultoria B é composta por 35 profissionais e, desses, catorze têm formação em Serviço Social, ocupando os seguintes cargos: um gerente de operações, um executivo de contas, um gerente de rede credenciada, dez consultores de atendimento, que são assistentes sociais, e um estagiário de Serviço Social. Recentemente, todos os profissionais da consultoria de autônomos passaram a ser contratados celetistas.

$\mathrm{O}$ atendimento aos empregados (das empresas contratantes) que recorrem ao PAE, principal produto da consultoria, ocorre a partir de uma central de atendimento, por um consultor especializado, que são psicólogos e assistentes sociais, instalados internamente na consultoria. Esses profissionais não são responsáveis pelos atendimentos externos. A partir de sistema informatizado, é identificado o cliente, o programa contratado, se o PAE, o número de sessões, que geralmente são seis, para resolução do caso apresentado, que pode variar a cada ligação. Os consultores fazem a triagem inicial, orientam ou encaminham para profissionais da rede credenciada e acompanham o caso até que seja finalizado.

Partindo do ano de constituição das consultorias - 1998 e 2000 - , constata-se que ambas vêm suprir, para as grandes empresas, uma demanda iniciada nos anos 1980, relacionada à política gerencial de recursos humanos de extensa diversidade de planos de benefícios e serviços sociais. Esse período é marcado pelo avanço tecnológico nas empresas e necessidade de envolvimento dos empregados para o alcance da produtividade e da qualidade.

Paralelamente, outra tendência que se inicia, nesse período, é a terceirização, visando reduzir os quadros e setores de trabalho que não representassem as atividades-fim da empresa e que se expressam também como forma de aumentar a lucratividade. Com isso, várias áreas administrativas, muitas relacionadas a recursos humanos - campo da prática do profissional do Serviço Social —, são entregues a terceiros, a consultorias especializadas. 
Os serviços oferecidos pelas Consultorias A e B, no campo do Serviço Social, referem-se às "velhas demandas", expressas em intervenções, e não em ações profissionais, ${ }^{10}$ com os empregados das empresas contratantes, para situações pontuais, na maioria de caráter individual, com a finalidade de orientar sobre como obter bens ou acesso a serviços.

Evidenciam-se também a manutenção de práticas vinculadas às relações de trabalho, já que os consultores são requisitados para atender problemas pessoais que interferem na produtividade. As questões de natureza psicossocial associam-se aos atendimentos a problemas não relacionados diretamente com o processo de trabalho, mas a questões de caráter humanitário, função tradicional da profissão. Pode-se inferir que os profissionais do Serviço Social, nas consultorias pesquisadas, desenvolvem atividades instituídas (pelas consultorias e empresas), e não são envolvidos em demandas oriundas das novas tecnologias de gerenciamento, como, por exemplo, os programas de formação e qualificação da mão de obra, verificadas em estudos de Serra (2010) e Cesar (2010) sobre as demandas apresentadas ao Serviço Social advindas da reestruturação produtiva.

As duas consultorias oferecem às empresas clientes o esquema de trabalho por 24 horas, e isso significa que os consultores ficam de sobreaviso para atendimentos emergenciais aos empregados. O esquema exige, do profissional de plantão, disponibilidade após o expediente de trabalho (geralmente noite e madrugada) e nos fins de semana. $\mathrm{O}$ acionamento é feito por telefone móvel, e o consultor poderá resolver a situação à distância, ou acionar um profissional da rede credenciada para conduzir o caso. $\mathrm{Na}$ Consultoria $\mathrm{A}$, o consultor poderá ainda comparecer ao local do fato, se estiver dentro da área de sua atuação.

$\mathrm{O}$ atendimento 24 horas disponibilizado às empresas exige dos profissionais das consultorias a flexibilidade das condições de trabalho para o atendimento a empregados da era globalizada, ocasionada a partir da abertura dos mercados. A abrangência oferecida pelas consultorias (várias localidades no Brasil e na América Latina) evidenciam que as consultorias também flexibilizaram a sua mão de obra.

Sobre a relação estabelecida com o empregado atendido, as consultoras são unânimes em relatar que se cria uma relação de confiança, inclusive naqueles casos

10. A partir de Ana Vasconcelos (2010) verifica-se que as demandas ao Serviço Social, em tempos de hegemonia do capital, não exigem, nas intervenções empreendidas, mais que um profissional que promova a "humanização" das relações pessoais e o acesso "eficiente" a um mínimo para a sobrevivência, por meio de escuta atenta e bom acolhimento. 
em que o atendimento não se dá pelo mesmo profissional, ou é feito apenas por telefone. Na Consultoria B, onde a totalidade dos casos é atendida a distância, relata-se também a criação de vínculos. As entrevistadas revelam que a confidencialidade, confiabilidade e disponibilidade do serviço 24 horas são as principais vantagens para os empregados. Lembrando que esse é o ponto de vista dos assistentes sociais, uma vez que a pesquisa não abrangeu os usuários dos serviços a respeito do assunto.

O tipo de atendimento prestado aos empregados das empresas contratantes é considerado como de caráter orientador pelas profissionais da Consultoria $\mathrm{B}$, e orientador e educador pelos profissionais da Consultoria A, evidenciando que a determinação dos empregadores (no caso aqui consultoria e empresa) influencia a finalidade da função do Serviço Social nesse ambiente. Confirmam-se as ponderações de Freire (2010), a respeito do caráter orientador e educativo, que adquire a intervenção do consultor externo, quando é dirigida ao empregado.

A confidencialidade dos dados do empregado é preservada. Para as empresas existe estatística de atendimento por demanda, para identificar situações que mereçam intervenções preventivas ou desenvolvimento de programa que visem à redução da incidência. Diante dessa realidade, as consultoras confirmam o que geralmente acontece com a atuação profissional nas empresas privadas, ou seja, a autonomia relativa, numa margem limitada.

O relato de uma das entrevistadas da Consultoria B exemplifica o fato: "O empregador recebe relatórios demográficos e por demanda, com o propósito de a empresa, a partir daí, desenvolver ações preventivas, mas não sabemos se desenvolve".

$\mathrm{Na}$ Consultoria A, o relato foi similar, já que, eventualmente, se reúnem com os representantes das empresas clientes e, quando solicitado, podem propor ações. "A consultoria tem um programa para o cliente acessar as estatísticas de atendimento, através de senha própria. Com isso, pode fazer o monitoramento das demandas e custo mensal, e podemos, em conjunto, propor ações preventivas."

Quanto à forma de contratação das assistentes sociais, especialmente as consultoras em Serviço Social, que são autônomas, nota-se que as profissionais não se sentem desprotegidas pelo fato de serem subcontratadas pela consultoria, e verificou-se também que buscam alternativas como forma de se preparar para situações futuras de aposentadoria e desemprego. Não reconhecem, como forma de precarização do trabalho, o fato de não serem trabalhadoras com vínculo empregatício. 
Essa constatação remete às ponderações de Druck (2009), a respeito da institucionalização da precarização do trabalho, e aqui as consultoras consideram natural sua condição de profissional terceirizado.

É relevante o número de assistentes sociais prestadores de serviço na rede credenciada. Entre as duas consultorias contabilizam-se, aproximadamente, 3.700 assistentes sociais, distribuídos em várias localidades (Brasil e América Latina) para atendimentos diversos, evidenciando que muitos desses profissionais têm mais de um vínculo empregatício, ou apenas esse trabalho de caráter eventual das consultorias. Conforme relato de uma das entrevistadas, da Consultoria A, "a maioria desses profissionais têm o seu trabalho, e prestam serviço para a consultoria quando acionados".

Outro dado relevante, revelado a partir das características das consultorias, é que a maioria dos clientes que terceirizam as atividades de assistentes sociais é composta de empresas privadas. Essas empresas representam 95\% dos clientes na Consultoria A e $98,5 \%$ a Consultoria B. Foi considerado o número de clientes informado pelas consultorias.

Considerando-se que na Consultoria B, recentemente, as assistentes sociais, consultoras de atendimento, passaram de autônomas para celetistas, e que, na Consultoria A, as consultoras em Serviço Social são autônomas, ${ }^{11}$ conclui-se, a partir do levantamento, que essas consultorias representam uma tendência à informalidade do trabalho do assistente social.

Com relação às características profissionais que os assistentes sociais consideram importantes para trabalhar na consultoria e, consequentemente, prestar serviços nas empresas, a pesquisadora elegeu doze itens para serem avaliados pelas profissionais entrevistadas, com nota de um a dez delas. Apenas o item confiança recebeu nota máxima das entrevistadas. Os outros, por ordem crescente, foram: bom intermediador de relações, compreensível, com foco na humanização do local de trabalho, polivalente, conhecedor dos critérios para prestação de serviços sociais, bom interlocutor da empresa, com qualificação profissional, com perfil educador e orientador, assertividade no assessoramento à gerência, boa capacidade técnica e qualificação intelectual.

Confirma-se, nas consultorias, assim como nas empresas privadas, que as novas modalidades de gestão da força de trabalho requerem, como característica

11. A Consultoria A tem quinze assistentes sociais, sendo cinco celetistas e dez autônomas. 
básica do assistente social, a confiabilidade e o bom relacionamento, para o envolvimento com os objetivos da empresa. Evidencia-se que não há requisitos com relação às características profissionais citadas no Código de Ética profissional, que dizem respeito ao "técnico competente teórica, técnica e politicamente" (p. 20).

As entrevistadas reconhecem o assistente social como um profissional estratégico na consultoria, capacitado para o atendimento, e acreditam no crescimento do número de empresas de consultoria com esse tipo de prestação de serviço, portanto, no aumento de vagas para os profissionais no mercado de trabalho.

Sobre as vantagens em trabalhar nas consultorias, são diversos os posicionamentos dos assistentes sociais, todos positivos, com relação à experiência que as relações de trabalho proporcionam ao profissional. Os destaques são para a experiência adquirida com a variedade de casos de atendimentos, o incentivo à capacitação demandada pelos atendimentos, a troca de experiências entre os profissionais, e também o conhecimento diversificado das realidades empresariais.

As representantes das consultorias destacam a importância da prestação de serviços para os empregadores (empresa) que têm equipes de empregados na área comercial, ou com um contingente de trabalhadores em atividades externas. $\mathrm{O}$ formato do serviço proporcionado pelas consultorias, cada qual com um nível de abrangência, 24 horas por dia, possibilita cobertura integral ao atendimento dos empregados e familiares em várias localidades, seja Brasil ou na América Latina.

$\mathrm{Na}$ opinião das assistentes sociais, as vantagens para os empregadores se estendem além das questões operacionais. Nos relatos, apontam questões financeiras, favoráveis às empresas contratantes, em terceirizar a atividade, e também vantagens oferecidas pela especialização do serviço, e formato na disponibilização - tempo, recursos e abrangência. Embora não mencionem o conceito flexibilização, é isso que se constata e remete a Graça Druck (2002) sobre as formas concretas que se difundem em todas as atividades e lugares.

Ainda sobre a dinâmica do trabalho das assistentes sociais nas consultorias, as entrevistadas foram questionadas se as atividades se constituíam em competências e atribuições dos assistentes sociais. A questão não teve o objetivo de investigar o conhecimento dos profissionais acerca da legislação profissional. A pergunta iniciou-se com a explicação sobre o conceito dos termos, ou seja, as atividades de competências como sendo aquelas que podem ser realizadas tanto pelo assistente social quanto por outros profissionais, e as atribuições privativas como sendo as atividades exclusivas dos assistentes sociais. As respostas foram $100 \%$ afirmativas 
para as duas questões, mas nota-se que os profissionais confundem os termos competências e atribuições, o que pode acontecer levando-se em conta o redimensionamento dos espaços ocupacionais e das demandas que definem novas competências ao assistente social.

Iamamoto (2002), em artigo a respeito dos espaços ocupacionais e trabalho do assistente social na atualidade, alerta que as alterações nas demandas interferem nas funções dos assistentes sociais que passam a executá-las, mas, "muitas vezes, não são por eles reconhecidos como atribuições privativas, tal como estabelecidas tradicionalmente" (p. 35).

Completando o pensamento a respeito das alterações que se processam nas demandas, com o qual esta pesquisadora concorda plenamente, a autora discorre que os espaços ocupacionais e as fronteiras profissionais sofrem significativas alterações, pois são resultantes históricos e, portanto, móveis e transitórias (Iamamoto, 2002).

\section{Algumas consideraç̧ões finais}

Conforme se demonstrou ao longo deste artigo, as consultorias empresariais apresentam-se como contingente de trabalho profissional e, independentemente do vínculo empregatício - seja no regime celetista ou na condição de autônomo os assistentes sociais são contratados, não para trabalhos profissionais de assessoria/ consultoria, no sentido pleno da palavra, como estudado com Matos $(2009,2010)$ e Freire (2010), ou com a finalidade de transferir conhecimentos necessários à continuidade do funcionamento dos serviços implantados, conforme visto com Orlickas (2001). Pela descrição, nas entrevistas, os atendimentos prestados fazem parte das atividades específicas e especializadas do assistente social, visando aos objetivos empresariais tanto das consultorias quanto das empresas clientes, de melhoria da qualidade de vida e trabalho dos empregados e do clima organizacional, voltados para a produtividade e a lucratividade.

As características das consultorias permitem a reflexão de que os impactos da reestruturação produtiva nas empresas impulsionaram a constituição de prestadores de serviços, em que a hegemonia e a subordinação (ao grande empresariado) existem, mesmo que de forma ocultada.

As consultorias, nas quais trabalham os assistentes sociais entrevistados, se constituíram no período 1998-2000, no auge do toyotismo e da reestruturação 
produtiva brasileira, marcados, entre outros, pelo neoliberalismo intensificado no governo Fernando Henrique Cardoso, em que a austeridade no gasto público, as privatizações, a reestruturação das políticas sociais, a desregulamentação e a flexibilização das relações trabalhistas são algumas características marcantes.

O retardamento na implementação e na efetivação dos direitos sociais postos pela Constituição federal de 1988, a protelação na efetivação das coberturas públicas, levam as empresas, a partir de seus interesses, a ampliar seus benefícios ocupacionais, práticas essas iniciadas nos anos 1980. Ao mesmo tempo, a lógica do mercado exige competitividade, produtividade, e lucratividade. Para isso, as empresas apoiam-se na flexibilidade dos processos de trabalho, que, entre outros fatores, se expressam na terceirização.

As consultorias especializadas em gestão de pessoas surgem, para as empresas, num momento em que a ampliação das políticas de recursos humanos, principalmente e não só, é caracterizada pela combinação de sistema de benefícios e serviços sociais como políticas de incentivo à produtividade do trabalho. Novas exigências são requeridas ao assistente social, na conjuntura atual. Competências e atribuições misturam-se com intervenções tradicionais, em novos contextos, próprios da contemporaneidade, como, por exemplo, intervenções nos casos provenientes de incidentes críticos, de sequestro, assaltos, desastres, acidentes etc.

Para atender às necessidades dos empregados, as consultorias informatizam-se, requerem profissionais competentes, com aptidão para responder por vários assuntos, confiáveis, bem relacionados (no ambiente das consultorias e empresarial), dinâmicos, proativos, polivalentes, que tenham disponibilidade para o trabalho por 24 horas (quando nos sobreavisos) e de forma abrangente (rede credenciada). O esquema de trabalho para atender a um trabalhador globalizado requer disponibilidade de serviço durante 24 horas e amplo nível de abrangência (no caso do Brasil e América Latina) e, com isso, organização em rede e equipes internas enxutas.

A flexibilidade apresentada pelas consultorias atende ao formato exigido pelas empresas. A dinâmica de trabalho e o esquema montado para o atendimento aos empregados das empresas contratantes - a distância, presencial, pela central de atendimento - demonstram que não só as empresas flexibilizaram a sua produção, mediante a desconcentração industrial ou a horizontalização produtiva, expressa na terceirização, mas as consultorias também.

O pressuposto de que, em empresas privadas, assim como nos serviços públicos, a prestação de serviços dos assistentes sociais, de forma terceirizada, interme- 
diada pelas consultorias empresariais, era verificável, nas formas de trabalho autônomo, temporário, por projeto, por tarefa, pode ser constatada por meio do conhecimento da constituição dos recursos humanos das consultorias participantes do estudo.

Os assistentes sociais, na condição de profissionais autônomos, envolvidos direta e internamente em uma das consultorias, prestando serviços para as empresas, mais os assistentes sociais da rede credenciada das duas consultorias, somam aproximadamente 3.700 profissionais. Essa verificação permite deduzir que as consultorias possivelmente sejam uma tendência de informalização do trabalho do assistente social, sob a aparência de prestação de serviços autônomos. Deve-se lembrar que foram identificadas cinco consultorias e que, portanto, esse número tende a ser maior.

As condições de trabalho flexíveis, o domínio diversificado de informações, o nível de abrangência do alcance para o atendimento, o trabalho part time são os requisitos de empresas da era globalizada para essas consultorias, no atendimento à reprodução da sua força de trabalho. A disponibilidade em tempo integral para situações emergenciais, por demanda, remete ao modo just in time, característica amplamente difundida na reestruturação produtiva. Os atendimentos de caráter individual, orientador, relacionados à busca por apoio, informação, encaminhamentos, aconselhamentos, para situações pontuais e emergenciais, condicionam a forma e os resultados do trabalho do assistente social e reiteram que a prática se dê num setor que é contraditório, por envolver relações entre capital e trabalho.

Conclui-se que, na gestão organizacional, as consultorias seguem o mesmo padrão adotado pelas empresas, ou seja, se apropriam dos processos de reestruturação produtiva, na forma de organização e na obtenção de lucro. A centralidade está nos interesses dos processos produtivos das empresas clientes, tornando-se secundária a perspectiva de ação do assistente social, com o empregado presente no projeto ético-político profissional. Isso não deve ser considerado como crítica, uma vez que a incidência não está somente na esfera empresarial.

O desafio é para o profissional que, sem negar sua condição de trabalhador assalariado, deve reconhecer que "há espaço para a defesa do projeto profissional em qualquer local, público ou privado, em que o assistente social é requisitado a intervir" (Couto, 2009, p. 652).

Um bom começo, conforme cita a autora, é o profissional estabelecer o que a profissão tem a oferecer naquele espaço ocupacional, como subsídio para o atendi- 
mento das demandas, de forma que possa manter o compromisso com os valores anunciados no Código de Ética e garantidos na lei de regulamentação profissional.

\section{Recebido em 20/7/2012 - Aprovado em 11/3/2013}

\section{Referências bibliográficas}

AMARAL, Angela Santana de; CESAR, Mônica. O trabalho do assistente social nas empresas capitalistas. In: CFESS/ABEPSS (Orgs.). Serviço social: direitos e competências profissionais. Brasília: CFESS/Abepss, 2009.

BOSCHETTI, Ivanete. Condições de trabalho e a luta dos(as) assistentes sociais pela jornada semanal de 30 horas. Serviço Social \& Sociedade, São Paulo, n. 107, jul./set. 2011.

CESAR, Mônica de Jesus. Serviço Social e reestruturação industrial: requisições, competências e condições de trabalho profissional. In: MOTA, Ana Elizabete (Org.). A nova fábrica de consensos. 5. ed. São Paulo: Cortez, 2010.

CÓDIGO DE ÉTICA DO/AASSISTENTE SOCIAL E LEI N. 8.662/93 [de regulamentação da profissão]. 9. ed. rev. e atual. Brasília: Conselho Federal de Serviço Social, 2011.

COUTO, Berenice Rojas. Formulação de projeto de trabalho profissional. In: CFESS/ABESS (Orgs.). Serviço social: direitos sociais e competências profissionais. Brasília: CFESS/ Abepss, 2009.

DAU, Denise M. A expansão da terceirização no Brasil e a estratégia da CUT de enfrentamento à precarização do trabalho. In: ; JACOME, Iram; CONCEIÇÃO, Jefferson J. (Orgs.). Terceirização no Brasil: do discurso da inovação à precarização do trabalho. São Paulo: Annablume, 2009.

DIEESE (Departamento Intersindical de Estatísticas e Estudos Socioeconômicos). O processo de terceirização e seus efeitos sobre os trabalhadores no Brasil. Dieese, 2011. Disponível em: <www.mte.gov.br/observatorio/prod03_2007.pdf>. Acesso em: 10 dez. 2011.

DRUCK, Graça. Terceirização: (des)fordizando a fábrica: um estudo do complexo petroquímico. São Paulo: Boitempo, 1999.

. Flexibilização e precarização: formas contemporâneas de dominação do trabalho. Caderno CRH, Salvador, n. 37, p. 11-22, 2002. Disponível em: <http://www.flexibilização. ufba.br/RCRH2006-270.graca.pdf>. Acesso em: 15 dez. 2011. 
DRUCK, Graça. Principais indicadores da precarização social do trabalho no Brasil [versão preliminar]. In: CONGRESSO BRASILEIRO DE SOCIOLOGIA, 15., Anais..., 2009. Disponível em: <www.coloquio-sso.blogspot.com/2010/04/coloquio.html>. Acesso em: 15 dez. 2011.

; FRANCO, Tânia. A terceirização no Brasil: velho e novo fenômeno. Laboreal, v. IV, n. 2, p. 83-94, 2008. Disponível em: <http://laboreal.up.pt/media/artigos/198/83-94pt. pdf>. Acesso em: 1odez. 2011.

FREIRE, Lúcia M. B. Assessoria e consultoria a gestores e trabalhadores como trabalho do assistente social. In: BRAVO, Maria I. S.; MATOS, Maurílio C. de (Orgs.). Assessoria, consultoria \& Serviço Social. 2. ed. São Paulo: Cortez, 2010.

IAMAMOTO, Marilda V. Projeto profissional, espaços ocupacionais e trabalho do assistente social na atualidade. Atribuições privativas do assistente social. Brasília: CFESS, 2002.

MATOS, Maurílio C. Assessoria, consultoria, auditoria, supervisão técnica. In: CFESS/ ABEPSS (Orgs.). Serviço Social: direitos sociais e competências profissionais. Brasília: Abepss, 2009.

Assessoria e consultoria: reflexões para o Serviço Social. In: ; BRAVO, Maria I. S. (Orgs.). Assessoria, consultoria \& Serviço Social. 2. ed. São Paulo: Cortez, 2010. MOTA, Ana Elizabete da; AMARAL, Angela S. do. Reestruturação do capital, fragmentação do trabalho e serviço social. In: (Org.). A nova fábrica de consensos. 5. ed. São Paulo: Cortez, 2010.

OLIVEIRA, Djalma de P. R. Manual de consultoria empresarial. 5. ed. São Paulo: Atlas, 2004.

ORLICKAS, Elizenda. Consultoria interna de recursos humanos. São Paulo: Futura, 2001. RAICHELIS, Raquel. O assistente social como trabalhador assalariado: desafios frente às violações de seus direitos. Serviço Social \& Sociedade, São Paulo, n. 107, jul./set. 2011.

SERRA, Rose M. S. Crise da materialidade no serviço social: repercussões no mercado profissional. 3. ed. São Paulo: Cortez, 2010.

VASCONCELOS, Ana M. Prefácio. In: BRAVO, Maria I. S.; MATOS, Maurílio C. de (Orgs.). Assessoria, consultoria \& Serviço Social. 2. ed. São Paulo: Cortez, 2010. 